\title{
Evaluation of Reproductive Health Statues in Afghanistan
}

\author{
Aminullah Mahboobi ${ }^{1}$ \\ ${ }^{1}$ MPH Student, Kandahar, Afghanistan \\ Correspondence: Aminullah Mahboobi Kandahar, MPH Student, Kandahar, Afghanistan. Tel: 93-799-813-830. \\ E-mail: aminullahkochi@yahoo.com
}

Received: April 9, 2018; Accepted: April 25, 2018; Published: May 9, 2018

\begin{abstract}
In the past 16 years, Afghanistan has formulated the first national development strategy, health and nutrition policy. The reproductive health policy formulated in 2002 was completed for the first time. Reproductive health strategies BPHS and EPHS are developed and updated every five years. We analyze the changes through data analysis and comparison.
\end{abstract}

Keywords: Afghanistan, reproductive health, evaluation, reproductive health policy, WHO

\section{Introduction}

\subsection{Reproductive Health Definition}

WHO defined health as a state of complete physical, mental and social well-being, and not merely the absence of disease or infirmity, reproductive health addresses the reproductive processes, functions and system at all stages of life. Reproductive health, therefore, implies that people are able to have a responsible, satisfying and safe sex life and that they have the capability to reproduce and the freedom to decide if, when and how often to do so. (www.who.int).

Worldwide, approximately 830 women died every single day due to complications during pregnancy or childbirth in 2015. Reducing the global maternal mortality ratio (MMR) from 216 per 100000 live births in 2015 to less than 70 per 100000 live births by 2030 will require a global annual rate of reduction of at least $7.5 \%$ which is more than triple the annual rate of reduction that was achieved between 1990 and 2015. Most maternal deaths are preventable, as the necessary medical interventions are well known. It is therefore crucially important to increase women's access to quality care before, during and after childbirth. In 2016, a trained midwife, doctor, globally did not assist millions of births or nurse, with only $78 \%$ of births were in the presence of a skilled birth attendant.

In $2016,77 \%$ of women of reproductive age who were married or in-union had their family planning need met with a modern contraceptive method. While nine out of 10 women in the WHO Western Pacific Region had their family planning need satisfied, only half of women in the WHO African Region did (4). Globally, the adolescent birth rate in 2015 was 44.1 per 1000 adolescent girls aged 15-19 years. The global under-five mortality rate in 2015 was 43 per 1000 live births, while the neonatal mortality rate was 19 per 1000 live births - representing declines of $44 \%$ and $37 \%$ respectively compared to the rates in 2000 .

Globally in 2016, there were 155 million children under the age of five who were stunted (too short for their age), 52 million wasted (too light for their height) and 41 million overweight (too heavy for their height). Stunting prevalence was highest (34\%) in the WHO African Region and the WHO South-East Asia Region. Both the highest prevalence of wasting (15.3\%) and number of wasted children (27 million) were found in the WHO South-East Asia Region. Between 2000 and 2016, the number of overweight children under the age of five increased globally by $33 \%$ which replicate the poor ANC and PNC services which is crucial needed part of Maternal health.

Globally in 2016, there were 36.7 millions of people who are living with HIV. From these 36.7 million people who are living with HIV $54 \%$ of adults and $43 \%$ children living with HIV who are currently receiving lifelong antiretroviral therapy.(World Health Organization 2017)

\subsection{Reproductive Health Background}

For the first time in 1960, UNFPA rise the issue about rapid growth population, also IUD and modern contraceptive become to medical field after rising this concern, in 1972 World Health Organization was conducted special research training of Human reproduction. The Greatest improvement was started after the international conference on pupation and development, which was held in Cairo Egypt from (5-13) September 1994. The meeting was 
called by UNFPA (United Nation fund for population), there was participated Representative from 179 government, the action of this population and the Key Actions for its further implementation, which were adopted by the United Nations General Assembly in July 1999.

\subsection{Afghanistan Reproductive Health Background}

Still Afghanistan has been suffering from high maternal (1291/100000), Children (55/1000 live birth) neonatal (45/1000 live births) mortality rate among the county, which much quit high in hole world and Region level.

Prior to the war, Afghan health and health services were very poor. In 1960, the infant and child mortality rates were 215 and 360 per 1000 live births; the total fertility rate was 7.7. The government mostly provided health services at central level, but there was very little health services outside the main cities. During the war between 1979- 1990, Afghanistan health system and infrastructure destroyed, many experts migrant to foreign countries and some of them have been killed. Poor health services has provided to Afghan people who have been leaved inside Afghanistan.

Following the Soviet invasion in December 1979, the international response to provide health care was prompt. By June 1980, three French NGOs were operating inside Afghanistan. A major renewed effort started in 1986 with the Afghan Health Sector Support Project, a USAID-funded project implemented by Management Sciences for Health (MSH). They worked with regional health committees to support 300 health facilities and trained 2,200 male basic health workers, which who equipped with basic equipment and supply. Some Female health workers trained on basic health care to attend skill birth delivery and provided health education for women.(Aitken 2003).

\subsection{Health System in Transition Phase}

An early 2002 an important policy decision was made to contract out delivery of health services to local and international NGOs, with the MOH adopting a stewardship role for the nation's health services. At the Joint Donor Mission in March to April 2002, three options for delivering services seemed to be possible:

$>$ Expand the Ministry of Health to provide services to all needed peoples.

$>$ Continue to fund NGOs with little control by government, or

$>$ Make Performance-based Partnership Agreements (PPAs) between the MOH and NGOs, which would allow the MOH to utilize existing NGO capacity to deliver services while still maintaining control over the strategic direction of the health sector.

$>$ Basic Package of Health Services (BPHS) The initial draft of the BPHS was prepared in two weeks by a WHO consultant with minimal consultation. The results were published in March 2003

> First Reproductive health policy was published in 2003, and included a National Reproductive Health Strategy, 2003-2005, and National Standards for Antenatal care, Family Planning, Newborn Care and Post-partum Care; and a guideline on Safe Motherhood at Community level.

> Essential Package of Hospital Services: after the initial work on the BPHS was complete and implementation has been started, special attention has bee given to hospital care, and the Essential Package of Hospital Services (EPHS) was published in 2005.

$>$ In 2002, there were 467 midwives, five IHS schools have established in five Regional provinces of Afghanistan (Balkh, Herat, Kandahar, Nanagarhar and Kabul) these schools have established for those girls who has graduated from 12th class, and they will work in hospital and comprehensive health center. The decision has been made to train a new cadre of midwives, Community Midwives, who would be selected and trained to work in rural health centers.

> By 2006, there were 16 new Community Midwifery schools. In 2009, there are 22 schools. They are run by NGOs with funding from a variety of donors. By mid-2009, 1,961 new midwives had been trained; 1,675 (85\%) have been deployed, and $61 \%$ of health centers now have at least one midwife.

A health facility study has conducted in 2005 which was a comprehensive inventory of 912 facilities

and 117 hospitals. Of the hospitals, only $47 \%$ had female staff, and only $24 \%$ provided cesarean sections. Of the primary care centers, $48 \%$ provided antenatal care and deliveries, but only half of those were adequately equipped. Only $29 \%$ offered three or more methods of contraception. Female health professionals in the country constituted 90 out of 647 specialists, 605 out of 2203 general physicians, and 467 midwives. Forty percent (40\%) of health facilities had no female health worker, (World Health Organization 2017).

Fertility rates have been very high. TFRs of 6.23 or 6.8 are variously quoted together with a crude birth rate of 48 per 1000. The Taliban had banned the use of modern contraceptives in 1996, so supplies had been scarce. On the 
other hand, refugees returning from Pakistan and especially from Iran had become used to a good supply of contraceptives and some promotion of family planning.(Ministry of Public Health of Afghanistan 2015)

\section{Reproductive Health Components}

1. Quality family planning services( Promoting safe motherhood: prenatal, safe delivery and post-natal care, including breast feeding)

2. Prevention and treatment of infertility (Prevention and management of complications of unsafe abortion).

3. Safe abortion services(where not against the law)

4. Treatment of reproductive tract infections(including sexually transmitted infections)

5. Information and counseling on human sexuality(responsible parenthood and sexual and reproductive health)

6. Active discouragement of harmful practices(such as female genital mutilation and violence related to sexuality and reproduction)

7. Functional and accessible referral. (Worku and Gebresilassie 2008)

\subsection{Component of Afghanistan Reproductive Health}

Based on Afghanistan health policy and structure Reproductive health Directorate of Ministry of public health has changed on (Reproductive, Maternal, Neonatal, Child and Adolescent Health) directorate, which covered, bellow strategic Areas:

* Maternal Health(Improved quality and equity in access to maternal health care, Improved sustainable Midwifery related health services at health facilities level, increase utilization of maternal health care through mothers and their families, extend Maternal and Neonatal health services to community level).

* Neonatal health (High impact intervention expansion to all health facilities, Improved quality of neonatal health services at all level)

* Family planning(advocacy for FP, IEC campaign for to increase family plaining services utilization, increase access to FP services at community level, provision of different commodities of PF at HFs and community level, capacity building of Health care provider and inclusion of FP services in private sector all HFs)

* Child Health (implementation of IMNCI at community and health facility level and improve ICSP strategy at National level)

* Adolescence health (Prevention and treatment of childhood Illness, School health program, Reproductive and marriage counselling).

* Reproductive Age Disease (increase community awareness about STI, HIV, cervix cancer, prostate cancer, fistula )

\section{* General issues ( Distribution of RMN}

Services to Deprived people, Quality improvement of RMNCAH services, inter personal communication and counseling for RMNCAH health services, strengthening of Referral system, Inter sectorial collaboration between public and private sector, Gender and GBV, maternal and child Nutrition) (Republic and Health 2013)

For measuring of each part of RMNCAH it is need to some indicators to measure our progress to toward our National, Regional and international goals. First, we will define the indicator: A variable that measures one aspect of a program/project or health outcome. The indicators should be divided on different categories (input, process, output, outcome and impact indicators). World health assembly and other key health partners (world Health Organization, United Nation fund for children, United Nation fund for Population, World Bank, Uropean commission and United states.

Agency for International Development) set a set of RMNCAH indicators as a below:

1. Maternal mortality ratio (SDG 3.1.1)

2. Under-5 mortality rate (SDG 3.2.1)

3. Neonatal mortality rate (SDG 3.2.2)

4. Stillbirth rate

5. Adolescent mortality rate

I. Pregnancy-related Mortality ratio defined as all deaths that occur to women during pregnancy, during childbirth, and up to 2 months after birth or termination of a pregnancy. 
II. Total fertility rate: Average number of children a woman would bear during her lifetime, assuming her childbearing conforms to her age-specific fertility rate every year of her childbearing years (typically, age 15 to 49).

III. Contraceptive prevalence Rate Contraceptive prevalence rate is the proportion of women of reproductive age who are using (or whose partner is using) a contraceptive method at a given point in time (World Health Organization 2017)

\subsection{Reproductive Health Indicators}

I. Infant mortality Rate: It is the probability of dying between birth and exactly 1 year as expressed per 1000 live births $($ Infant $=$ child from birth to 1 year of age $)$.

II. It is the probability of dying of children $<5$ years in a given year X 1000/Total live births in the same year.

III. Based on WHO 2012 Report stillbirth rate in Afghanistan is 29/1000 live births.(Ministry of Public Health Kabul 2010)

Table 1. Reproductive health indicators summary sheet from 2002-2015

\begin{tabular}{|c|c|c|c|c|c|}
\hline & Indicator & 2003 MICS & 2006 AHS & 2010 AMS & 2015 AfDHS \\
\hline 1 & Maternal mortality ratio & $\begin{array}{l}1600 / 100000 \\
\text { live births }\end{array}$ & Nil & $\begin{array}{l}327 / 100000 \\
\text { live births }\end{array}$ & $\begin{array}{l}1291 / 100000 \\
\text { live births }\end{array}$ \\
\hline 2 & $\begin{array}{l}\text { Antenatal care by skilled } \\
\text { worker }\end{array}$ & $5 \%$ & $32 \%$ & $60 \%$ & $59 \%$ \\
\hline 3 & Skilled birth attendance & $6 \%$ & $19 \%$ & $34 \%$ & $48 \%$ \\
\hline 4 & Total fertility rate & $\begin{array}{l}6.23 \text { (Others } \\
\text { quote } 6.8)\end{array}$ & Nil & 5.1 & 5.3 \\
\hline 5 & Crude birth rate & 48 per 1000 & Nil & Nil & Nil \\
\hline 6 & Heard of contraceptives & $28 \%$ & Nil & $92 \%$ & $94 \%$ \\
\hline 7 & Contraceptive prevalence rate & $5 \%$ & $16 \%$ & $20 \%$ & $20 \%$ \\
\hline 8 & Infant Mortlity Rate & $165 / 1000$ & $129 / 1000$ & $77 / 1000$ & $45 / 1000$ \\
\hline 9 & Childe Mortility Rate & $257 / 1000$ & $191 / 1000$ & $97 / 1000$ & $55 / 1000$ \\
\hline
\end{tabular}

Source: Unicef Multi indicator survey 2003, Afghanistan health survey 2006, Afghanistan Mortality survey 2010 and Afghanistan health and Demographic survey 2015.

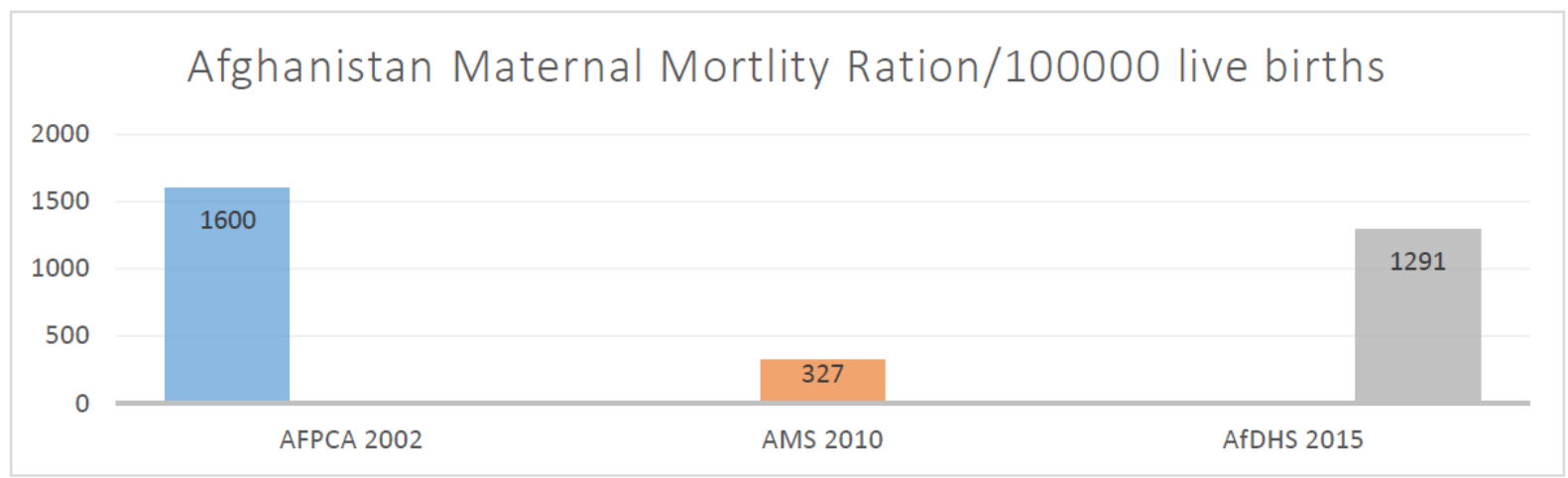

Figure 1. Afghanistan Maternal Mortlity Ration/100000 live births

Adapted from UNICEF Multi indicator survey 2003, Afghanistan health survey 2006, Afghanistan Mortality survey 2010 and Afghanistan health and Demographic survey 2015. it Describe Maternal Motility ratio in past 13 years, which has not progressed well, both 2010 and 2014 surveys data show some data discrepancy, will never find that much improvement in each region of world like in Afghanistan between (2002-2010).

Based on last survey information after 2010 the maternal mortality Ratio increased strongly, which has effected the previous progress, which has made between between2002 and 2010. May be there is some data collection error in first or second round Data collection, analysis or data interpretation or dissemination. 


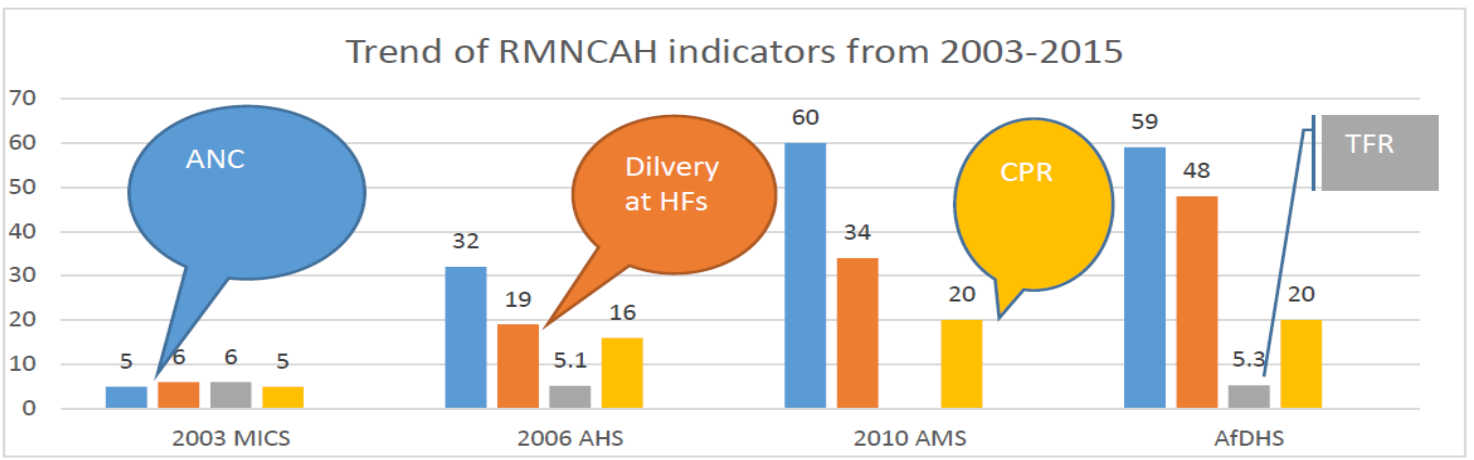

Figure 2. Trend of RMNCAH indicators from 2003-2015

The above chart describe ANC visits by skilled health provider has well improved from 2003 to 2010 but unfortunately in last 5years it progressed poorly, however much many female health provider trained, new health facilities stablished for white areas, many health project implemented.

Delivery at health facility by skilled health provider is improved during the past 15 year, in additional it has a big challenge for Afghan health system, still 52\% women has given births at home, which is a very serious condition, in any time after delivery she can face with serious complications post- partum hemorrhage, sepsis, prolonged labor and....etc.

PNC by skilled health provider have improved well during the past 15 years, the trend, of PNC is logical with Resources utilization, cost, staff increment, trainings, new learning Resource Packages and introduction of new high impact intervention to health system.

The high total fertility Rate and low contraceptive prevalence rate is still a biggest problem in Afghanistan among the developing country, tradition community, male decision-making power, migration, internally displacement, low educational level of male and female other causes which are affecting contraceptive prevalence and total fertility Rates.(Amare et al., 2009)

Above data is adapted from Afghanistan mortality survey 2010 which describe the timing maternal mortality, the 3 delay is the big cause of Maternal mortality.

1. Delay for seeking health care.

2. Delay in access to health care.

3. Delay in receiving health care.

\section{Timing of Pregnancy-Related Deaths}

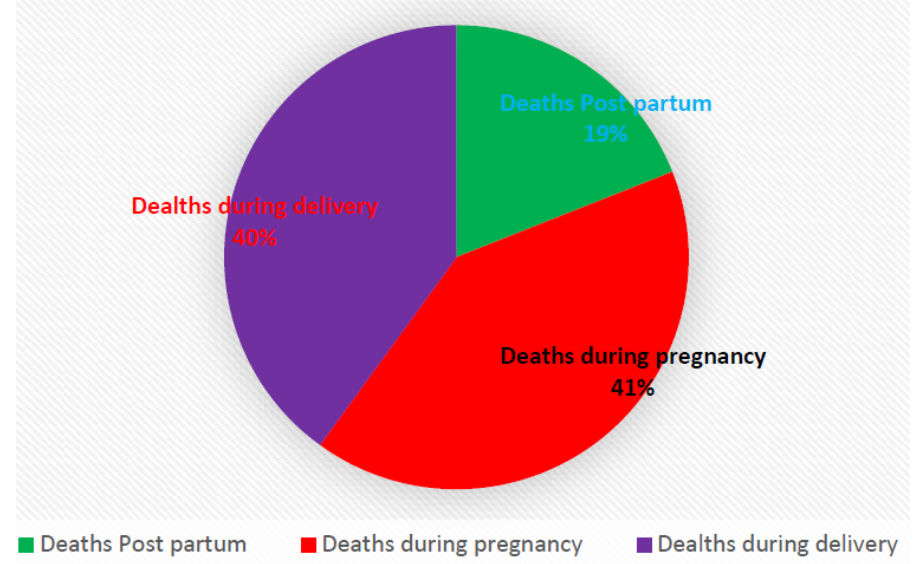

Figure 3. Timing of Pregnancy-Related Deaths

The first Delay occurring when the mother at home, who living alone or with her family but they have not informed the severity of health problem which mother suffering from, or family does not have resource to bring the mother to nearest health facility or a family is not able to make proper decision to utilize health services. 
The second delay is occurring in access to health services, both community and patient know the severity of problem but they do not have access to Health services.

It maybe there was no active health facilities to provide health services for patients or maybe there is no active community healthy works, lack of transportation system and lack of ambulance between primary and secondary health care.

Delay 3 is in receiving health care to patient it is usually occurring in health facilities, because there is no proper triage system for emergency patient and those patients who are referring from first line health facilities and community-by-community health worker.

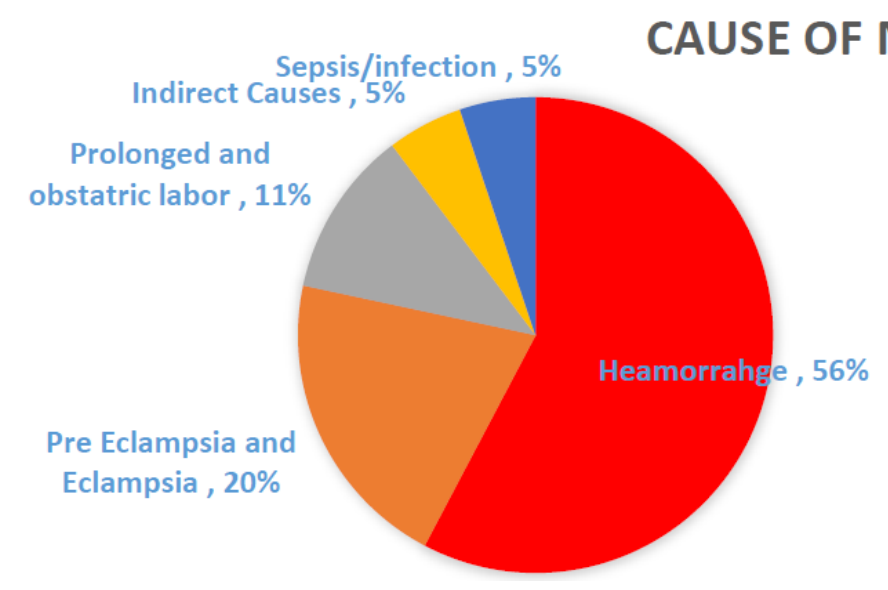

Figure 4. Cause of Maternal Deaths

\begin{abstract}
Adapted from Afghan motility survey 2010, still the biggest causes of afghan mother mortality is PPH(Post-partum hemorrhage) which is the leading cause for maternal mortality in Afghanistan, it has been occurring both at community and health facility level.
\end{abstract}

The second leading cause for maternal mortality in Afghanistan is Pre-eclampsia and eclampsia, quite much patient loss their life from it, at community level people have thought it has Gen and some time they have brought to mullah and other religious scholars.

The third leading cause for maternal mortality is prolongs labor, in rural health facilities midwifes and female doctors not able to diagnose prolong labor and abstractive labor, which caused maternal mortality.

At all $90 \%$ of maternal mortality, leading causes is preventable with very low income and

Resources at community and health facilities levels.

\title{
3. Conclusion
}

During the past 16 years, very important changes have been occurring in Afghanistan. First National Development strategy developed, Afghan Health and Nutrition policy developed, first finalized Reproductive health policy developed 2002. Reproductive health strategy Developed and renewed in each five years, BPHS and EPHS have made.

Afghanistan Health Priorities had set and shared with international community in Afghanistan national development Health strategy, new health facilities established. Access to health services increased from $16 \%$ to $80 \%$, Stewardship Role of Ministry of public health strengthened both at central and provincial level.

Health workforce increased through public and private Medical faculties and other educational institutions.

More than 5000 midwifes have been trained, standardized curriculum for both community and hospital midwifes were developed and has been implementing.

Afghanistan midwifery accreditation boards has established and all governmental midwifery programs have accredited, beside of these achievements, community nursing education program was started in at country level.

Afghan Medical council established, Afghan midwifery and Nursing associations, Afghan gynecology and Obstetrician society established. 
High impact interventions introduced to current health system, Infection prevention guideline adapted and all health facilities staff were trained, Basic emergency Obstetric care and Advance Emergency obstetric care, Postpartum hemorrhage, pre-eclampsia and eclampsia treatment guideline have developed and $80 \%$ health facilities staff were trained.

IMNCI guideline developed from UNICEF/WHO international guideline, all health facilities staffs have trained on IMNCI and has implemented.

HII(high impact intervention) guidelines have developed for( ORS\&Zinc, new treatment methods for PPH, Preeclampsia and eclampsia, Respectful Maternity care, essential health care for every baby, essential care for small , helping baby to birth.

\section{Recommendations}

1. MoPH, international Donor, National and international BPHS and EPHS implementing partners should be more focused on quality of health care.

2. Reproductive should be top priority for all National, Regional, provincial, district, public and private hospital.

3. Private hospital should provide RH services free or provide subsides for those clients who need it.

4. Each public and private university and institution should be have a fully equipped hospital for student's practical work.

5. Based on WHO standard 4 Basic emergency obstetric care and 1 compehsinve obstetric care center should be established for 500000 population therefore the number of health facilities with secondary and tertiary health service should be increased at National, Provincial and district level.

6. New health facilities will established for those white areas, which still does not have any kind of health facilities.

7. Afghanistan government should much quite focused on rural and urban health programs in close coordination with municipalities and rural rehabilitation program.

\section{References}

Aitken, I. (2003). Reproductive Health in Post-Conflict Afghanistan Case Study on Sexual and Reproductive Health Services during Reproductive Health Service Challenges.

Amare, H., Rodrigo, B., Ann, I., Edward, K., Mohammad, D. K., \& Shannon, W. (2009). Afghanistan Private Sector Health Survey. Global Health Technical Assistance Project, USAID, No. May.

Health Organization. https://doi.org/10.1017/CBO9781107415324.004

Ministry of Public Health Kabul, Afghanistan. (2010). Afghanistan Mortality Survey 2010. Mortality, No. August: $1-285$.

Ministry of Public Health of Afghanistan. (2015). National Health Policy.

Republic Islamic and Public Health. (2013). Islamic Republic of Afghanistan Ministry of Public Health National Child.

Worku, F., \& Samuel, G. (2008). Reproductive Health. Reproductive Health for Health Science Students, No. Md: 12.

World Health Organization. (2017). World Health Statistics 2017: Monitoring Health for The SDGs. World

\section{Copyrights}

Copyright for this article is retained by the author(s), with first publication rights granted to the journal.

This is an open-access article distributed under the terms and conditions of the Creative Commons Attribution license (http://creativecommons.org/licenses/by/4.0/). 